\title{
Characterization of Liquefied Wood Residues from Different Liquefaction Conditions
}

\author{
Hui Pan, ${ }^{1}$ Todd F. Shupe, ${ }^{1}$ Chung-Yun Hse ${ }^{2}$ \\ ${ }^{1}$ School of Renewable Natural Resources, Louisiana State University AgCenter, Baton Rouge, Louisiana 70803 \\ ${ }^{2}$ Southern Research Station, USDA Forest Service, Pineville, Louisiana 71360
}

Received 11 December 2006; accepted 23 February 2007

DOI 10.1002/app.26435

Published online 11 June 2007 in Wiley InterScience (www.interscience.wiley.com).

\begin{abstract}
The amount of wood residue is used as a measurement of the extent of wood liquefaction. Characterization of the residue from wood liquefaction provides a new approach to understand some fundamental aspects of the liquefaction reaction. Residues were characterized by wet chemical analyses, Fourier transform infrared (FTIR) spectroscopy, X-ray diffraction (XRD), and scanning electron microscopy (SEM). The Klason lignin content of the residues decreased, while the holocellulose and $\alpha$-cellulose contents increased as the phenol to wood ratio $(\mathrm{P} / \mathrm{W})$ increased. A peak at $1735 \mathrm{~cm}^{-1}$, which was attributed to the ester carbonyl group in xylan, disappeared in the FTIR spectra of the residues from liquefied wood under a sealed reaction sys-
\end{abstract}

tem, indicating significantly different effects of atmospheric versus sealed liquefaction. The crystallinity index of the residues was higher than that of the untreated wood particles and slightly increased with an increase in the $\mathrm{P} / \mathrm{W}$ ratio. The SEM images of the residues showed that the fiber bundles were reduced to small-sized bundles or even single fibers as the $\mathrm{P} / \mathrm{W}$ ratio increased from $1 / 1$ to $3 / 1$, which indicated that the lignin in the middle lamella had been dissolved prior to the cellulose during liquefaction. (c) 2007 Wiley Periodicals, Inc. J Appl Polym Sci 105: 3739-3746, 2007

Key words: wood liquefaction; phenol; residue; chemical analysis; FTIR

\section{INTRODUCTION}

Wood liquefaction, using a reagent solvent and an acid catalyst, has long been studied as a novel technique to utilize biomass as an alternative to petroleum-based products. Phenol is a commonly used reagent solvent for wood liquefaction. Wood liquefied with phenol can be developed into resol or novolac type phenolic resins. ${ }^{1,2} \mathrm{~A}$ variety of general studies have been conducted on wood liquefaction with phenol. ${ }^{3,4} \mathrm{~A}$ model compound of lignin has been used to demonstrate the reaction mechanism of lignin during wood liquefaction. ${ }^{5,6}$ However, a comprehensive understanding of the mechanism of wood liquefaction in the presence of phenol has not yet been clearly established, which is probably due to the complicated structure and composition of wood. Cellulose, hemicellulose, and lignin are the three main components of wood. The strong network of cellulose, hemicellulose, and lignin and the crystal structure of some regions of cellulose make wood extremely resistant to liquefaction, even under severe reaction conditions. Therefore, wood residue is always a part of a liquefied wood mixture, espe-

Correspondence to: T. F. Shupe (TShupe@agcenter.lsu.edu).

Journal of Applied Polymer Science, Vol. 105, 3739-3746 (2007) C 2007 Wiley Periodicals, Inc.

$\because$ WILEY (4)WILEY Perien cially when a weak acid is used as a catalyst. The residue content (i.e., the amount of wood residue remaining after liquefaction) usually is an evaluation of the extent of a liquefaction reaction. A comprehensive study on liquefied wood residue is still lacking. It is important to study the characteristics of the wood components after liquefaction. Research on liquefied wood residues provides a new approach to better understand some fundamental aspects of wood liquefaction. Therefore, the objective of this article is to characterize liquefied wood residues from different liquefaction conditions. First, quantitative analyses of cellulose, hemicellulose, and lignin of the residues were conducted. The changes in the functional groups of the residues were tracked by Fourier transform infrared spectroscopy (FTIR). The degree of crystallinity, which indicates the crystal and amorphous structure change in cellulose of the residues, was studied by X-ray diffraction (XRD). Finally, the structure and the surface morphology of the residues were investigated by scanning electronic microscopy (SEM).

\section{EXPERIMENTAL}

\section{Materials}

Chinese tallow (Triadica sebifera syn. Sapium sebiferum) tree wood was sawn on a laboratory table saw and the saw dust was collected. The particles were 
TABLE I

Liquefaction Variables and their Levels

\begin{tabular}{lccc}
\hline $\begin{array}{c}\text { Cooking } \\
\text { method }\end{array}$ & $\begin{array}{c}\text { Liquefaction } \\
\text { temperature }\end{array}$ & $\begin{array}{c}\text { Phenol to } \\
\text { wood ratio }\end{array}$ \\
\hline 1 & Atmospheric & $150^{\circ} \mathrm{C}$ & $1 / 1$ \\
2 & Sealed & $180^{\circ} \mathrm{C}$ & $2 / 1$ \\
3 & & & $3 / 1$ \\
\hline
\end{tabular}

oven dried at $105^{\circ} \mathrm{C}$ to a moisture content of $3-5 \%$ and then reduced in a Wiley mill to fine powder of 20-200 mesh. Liquid industrial grade phenol $(90 \%$ concentration) was used as the liquefaction reagent. All other chemicals were reagent grade.

\section{Preparation of liquefied wood and liquefied wood residues}

Wood powder, phenol, and oxalic acid were mixed in a container until a uniform mixture was obtained. The mixture was then transferred to a 1-L three-neck glass reactor equipped with a condenser and a stirring system. The liquefaction procedure was also conducted in a 1-L Parr reactor. The experimental variables and their levels are listed in Table I. Oxalic acid was used as a catalyst and its content was $5 \%$ based on the amount of phenol. The liquefied mixture was diluted with methanol and filtered with Whattman medium flow filter paper. The insoluble residues were oven dried at $105^{\circ} \mathrm{C}$ overnight and stored in a desiccator. The residue content of the liquefied wood was calculated by eq. (1):

$$
\text { Residue Content }(\%)=\left(W_{r}-W_{o}\right) \times 100
$$

where $W_{r}$ is the oven-dried weight of the solid wood residue after the filtration, and $W_{o}$ is the weight of the original wood powder.

\section{Chemical analyses}

The liquefied wood residues were first extracted in a Soxhlet apparatus to yield extractive-free materials in accordance with ASTM D1105-96, ${ }^{7}$ Klason lignin ASTM D1106-96, ${ }^{8}$ holocellulose ASTM D1104-56, and $\alpha$-cellulose ASTM D1103-60 $0^{10}$ were determined based on the extractive-free residues.

\section{FTIR spectroscopy}

The FTIR analysis of the liquefied wood residues was performed by a Nicolet Nexus 670 spectrometer equipped with a Thermo Nicolet Golden Gate MKII Single Reflection ATR accessory. A small amount of residues was applied directly on the diamond crystal.

\section{X-ray diffraction analysis}

The degree of crystallinity of the residues was measured by XRD. The liquefied wood residues from different liquefaction conditions were pressed into disks and analyzed with a PANalytical X'PERTPROSuper $X$-ray diffractometer. The $X$-ray diffractograms were recorded from $0^{\circ}$ to $40^{\circ}$ at a scanning speed of $1^{\circ} / \mathrm{s}$ and sampling rate of $2 \mathrm{data} / \mathrm{s}$. The crystallinity index $(\mathrm{CrI})$ of the liquefied wood residue was calculated using the Segal method ${ }^{11}$ per the following equation:

$$
\operatorname{CrI}(\%)=\frac{I_{002}-I_{\mathrm{am}}}{I_{002}} \times 100
$$

where $I_{002}$ is the intensity of the diffraction from the (002) plane at $2 \theta=22.6^{\circ}$, and $I_{\mathrm{am}}$ is the intensity of the background scatter measured at $2 \theta=18.5^{\circ}$.

\section{Scanning electron microscopy}

A SEI Qanta 200HV SEM was used to observe the structure and the surface morphology of the liquefied wood residues from different liquefaction conditions. The samples were coated with gold, using a vacuum sputter coater before subjected to the SEM.

\section{RESULTS AND DISCUSSION}

\section{Residue content}

The average residue content of liquefied wood from different liquefaction conditions is shown in Figure 1. The residue content consistently decreased as the phenol to wood ratio $(\mathrm{P} / \mathrm{W})$ increased from $1 / 1$ to $3 / 1$. The liquefied wood reacted in the sealed system had a substantially lower residue content than from

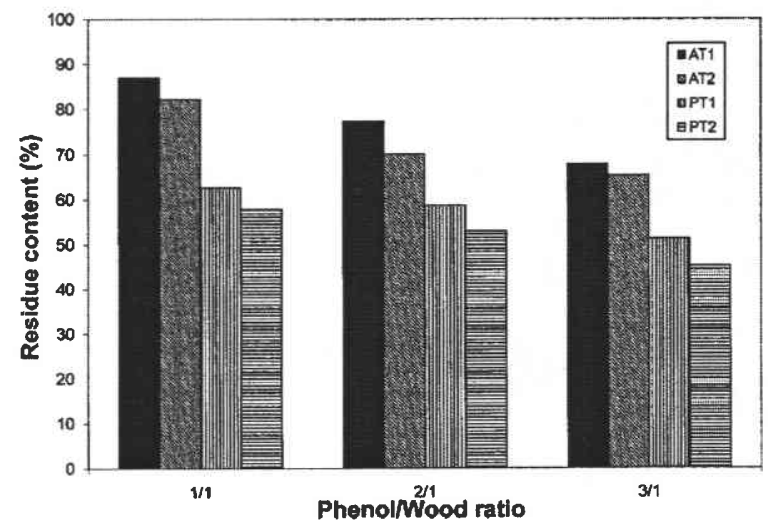

Figure 1 Average residue content of liquefied wood residues. (Note AT1 $=150^{\circ} \mathrm{C}$, atmospheric system; AT2 = $180^{\circ} \mathrm{C}$, atmospheric system; PT1 $=150^{\circ} \mathrm{C}$, sealed system; $\mathrm{PT} 2=180^{\circ} \mathrm{C}$, sealed system . 
TABLE II

Mean Chemical Composition Value of Liquefied Wood Residues

\begin{tabular}{|c|c|c|c|c|c|c|}
\hline \multirow[b]{2}{*}{$\mathrm{P} / \mathrm{W}$} & \multicolumn{2}{|c|}{ Klason Lignin (\%) } & \multicolumn{2}{|c|}{ Holocellulose (\%) } & \multicolumn{2}{|c|}{$\alpha$-cellulose (\%) } \\
\hline & $150^{\circ} \mathrm{C}$ & $180^{\circ} \mathrm{C}$ & $150^{\circ} \mathrm{C}$ & $180^{\circ} \mathrm{C}$ & $150^{\circ} \mathrm{C}$ & $180^{\circ} \mathrm{C}$ \\
\hline \multicolumn{7}{|c|}{ Atmospheric cooking } \\
\hline $1 / 1$ & $17.65(0.57)$ & $15.44(0.29)$ & $69.78(0.41)$ & $71.65(0.43)$ & $42.80(1.09)$ & $47.06(0.25)$ \\
\hline $2 / 1$ & $13.25(0.91)$ & $9.16(0.20)$ & $73.68(0.89)$ & $81.25(0.13)$ & $49.38(0.05)$ & $54.09(0.12)$ \\
\hline $3 / 1$ & $10.04(0.34)$ & $7.41(0.36)$ & $79.68(0.36)$ & $82.05(0.19)$ & $52.46(0.17)$ & $51.48(0.49)$ \\
\hline \multicolumn{7}{|c|}{ Sealed cooking } \\
\hline $1 / 1$ & $26.67(0.45)$ & $40.35(0.59)$ & $63.93(0.16)$ & $53.76(1.57)$ & $39.42(0.32)$ & $30.09(0.15)$ \\
\hline $2 / 1$ & $10.63(0.16)$ & $18.98(0.60)$ & $83.56(0.41)$ & $75.86(0.33)$ & $54.63(2.41)$ & $48.33(0.78)$ \\
\hline $3 / 1$ & $2.92(0.21)$ & $1.42(0.49)$ & $92.85(0.17)$ & $92.17(0.48)$ & $60.39(0.73)$ & $53.74(0.11)$ \\
\hline
\end{tabular}

The numbers in the parentheses are standard deviations.

the atmospheric system. The reason for this phenomenon can be attributed to the more thorough penetration of phenol into the wood powder in the sealed liquefaction system than in the atmospheric system. Therefore, more reaction sites in the wood powder can be reached by phenol in the former situation. It can also be seen in Figure 1 that liquefaction temperature has a significant effect on residue content of the liquefied wood. Liquefied wood reacted at $180^{\circ} \mathrm{C}$ had a lower residue content than that from $150^{\circ} \mathrm{C}$.

\section{Chemical analyses}

Table II presents the mean values of Klason lignin, holocellulose, and $\alpha$-cellulose contents of the liquefied wood residues from different liquefaction conditions. In general, the Klason lignin contents of the liquefied wood residue consistently decreased as $\mathrm{P} / \mathrm{W}$ ratio increased and were lower than that of the original Chinese tallow tree wood $(20.3 \%)^{12}$ except for the residue from $\mathrm{P} / \mathrm{W}$ ratio $1 / 1$ in the sealed system. The liquefied wood residue yielded a lower Klason lignin content at the higher temperature in the atmospheric system. These results were consistent with the residue content of the liquefied wood (Fig. 1) because the high temperature and $P / W$ ratio were expected to promote the extent of wood liquefaction reaction ${ }^{13}$ and lignin is the most reactive wood component in the liquefaction reaction. ${ }^{14}$ However, the liquefied wood residue in the sealed system yielded extremely high Klason lignin contents at $\mathrm{P} / \mathrm{W}$ ratio $1 / 1$. A possible explanation to this phenomenon might be the recondensation reaction of the decomposed lignin units. Several studies reported that the monomeric units of lignin have a tendency to undergo secondary condensation reactions. ${ }^{15,16} \mathrm{Pu}$ and Shiraishi ${ }^{14}$ found that the Klason lignin content of the residue gradually increased at lower $\mathrm{P} / \mathrm{W}$ ratios with an increase in reaction time. Furthermore, $\mathrm{Lin}^{13}$ reported that guaiacol, an intermediate of the liquefaction reaction of lignin model compound guaiacylglycerol- $\beta$-guaiacyl ether (GG), mostly remained intact in the reaction because of the existence of an excess amount of phenol, which competed with it in the nucleophilic reaction. Therefore, with an increase in $\mathrm{P} / \mathrm{W}$ ratio, the excess amount of phenol can also retard the tendency of the lignin recondensation reaction. However, in the process of solvolysis during wood liquefaction, it is also possible that the phenol reacted with the dissolved lignin to form an intermediate insoluble new substance that was retained in the residue, which in turn effected the Klason lignin determination.

Holocellulose consists of hemicellulose and cellulose. As listed in Table II, the average holocellulose content in the residue increased as the $P / W$ ratio increased. The residues from the higher liquefaction temperature (e.g., $180^{\circ} \mathrm{C}$ ) had a higher mean holocellulose content than from the lower temperature (e.g., $150^{\circ} \mathrm{C}$ ) in the atmospheric liquefaction system. The result is the opposite in the sealed liquefaction system. As mentioned earlier, lignin is the most susceptible component in wood that reacts with phenol during liquefaction. ${ }^{14}$ The higher the reaction temperature, the more lignin that was removed from the wood and dissolved into the solvent, and thus the relatively higher amount of residual holocellulose. Several studies have reported that the thermal degradation of wood occurs at around $200^{\circ} \mathrm{C} .^{17,18}$ However, the effect of temperature on thermal degradation of wood differs between wood species, and the characteristics of thermal degradation of the three wood components is different from each other. In general, the thermal degradation of lignin, hemicellulose, and cellulose occurs at around 100, 200, and $300^{\circ} \mathrm{C}$, respectively. ${ }^{17}$ However, with the additional factor of pressure associated with temperature in the reaction, thermal degradation in wood can be observed as low as $100^{\circ} \mathrm{C}^{18}$ The research of Stamm ${ }^{19}$ showed that heating in a sealed system causes more rapid degradation than heating in an open system. Therefore, the severe thermal degradation of holocel- 
lulose at $180^{\circ} \mathrm{C}$ in a sealed reaction system could be the reason for the lower holocellulose content when compared with that of the atmospheric system.

The $\alpha$-cellulose content of the residue showed a very similar trend with the holocellulose content. The influence of $\mathrm{P} / \mathrm{W}$ ratio, liquefaction temperature, and cooking method on $\alpha$-cellulose content of the residue are also similar with those of the holocellulose and have been discussed in the previous paragraph. The only difference between these two contents is that the residues from the higher liquefaction temperature (e.g., $180^{\circ} \mathrm{C}$ ) consistently had a lower $\alpha$-cellulose content than those from a liquefaction temperature of $150^{\circ} \mathrm{C}$, which could also be due to the degradation of cellulose at higher temperature.

\section{FTIR spectroscopy}

FTIR spectra of woody materials are complex because of the various functional groups that exist in wood components and the complicated chemical environment of the wood components. Many peaks in wood IR spectra are broad and often overlap with neighboring peaks. However, the FTIR spectra of the residues from atmospheric and sealed cooking systems did show some differences between each other and to that of the original wood (Fig. 2). A broad peak at around $3328 \mathrm{~cm}^{-1}$ is due to the $-\mathrm{OH}$ groups either from wood carbohydrates or lignin. ${ }^{20,21}$ The peak at $2900 \mathrm{~cm}^{-1}$ represents the $\mathrm{C}-\mathrm{H}$ stretch in methyl and methylene groups. ${ }^{22}$ These two peaks were displayed in every individual spectrum of the residue from the different liquefaction conditions.

An intense absorbance at $1735 \mathrm{~cm}^{-1}$ occurred in both spectra of original wood and residues from the

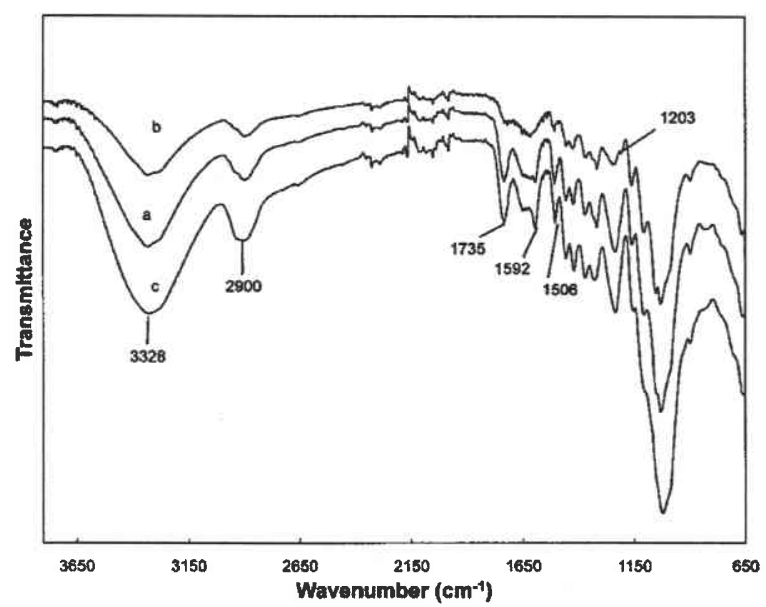

Figure 2 FTIR spectra of residues from atmospheric (Spectrum a), sealed cooking (Spectrum b), and untreated wood (Spectrum $c$ ). The $P / W$ ratio was $1 / 1$ and liquefaction temperature was $150^{\circ} \mathrm{C}$. atmospheric liquefaction systems, while it became a small shoulder or even disappeared (spectra not shown) in the spectra of residues from the sealed liquefaction systems, indicating different liquefaction reactions under pressurized metal reactor versus atmospheric glass reactor. It is known that the absorption bands from 1710 to $1740 \mathrm{~cm}^{-1}$ mainly arose from the carbonyl $(\mathrm{C}=\mathrm{O})$ stretch in unconjugated ketone, ester, or carboxylic groups in carbohydrates and not from lignin. ${ }^{20,23}$ It is also shown that carbonyl groups occur abundantly with the methyl and acetyl ester groups in pectin, the acetyl ester groups in xylan, and in the oxidative products of cellulose. ${ }^{24-26}$ However, the wood species used in this experiment, Chinese tallow tree (Triadica sebifera syn. Sapium sebiferum), is not rich in pectin, ${ }^{12}$ and the most profound effects of cellulose oxidation occurred at $250^{\circ} \mathrm{C}^{26}$ which is far beyond the temperature used in this experiment. Consequently, the absorbance band at $1735 \mathrm{~cm}^{-1}$ in the spectra in this experiment is most likely attributed to the ester carbonyl group in xylan. The phenomenon of the absence of the $1735 \mathrm{~cm}^{-1}$ band in the spectra of the residue from the sealed liquefaction system is very similar to that of the wood or other natural cellulosic fiber treated with sodium hydroxide $(\mathrm{NaOH}){ }^{27,28}$ This phenomenon of alkali treated natural fibers has been interpreted as the hydrolysis of the ester linkages in the xylan. ${ }^{29}$ Xylans are closely associated with other plant cell wall constituents, such as lignin and pectic polysaccharides, by ferulic acid or uronic acid through ester linkages. ${ }^{30,31}$ In the presence of alkalis, the hydroxyl ions cause the saponification of these ester linkages and peel off the hemicellulose from their neighboring lignin or cellulose into solution. ${ }^{32,33}$ Although the mechanism of the reaction to cause the disappearance of the peak at $1735 \mathrm{~cm}^{-1}$ in the spectra of the residues from the sealed liquefaction system is not quiet clear yet, it can be postulated that the hemicellulose in the sealed liquefaction system undergoes a similar deesterification process like the alkali treatment.

The absorbance at 1592 and $1506 \mathrm{~cm}^{-1}$ correspond to aromatic skeletal (lignin) vibrations. ${ }^{20}$ In general, the intensities of this peak diminished in the spectra of the liquefied wood residue from the atmospheric conditions and almost disappeared in that of the sealed condition, suggesting that the lignin might react to a greater extent under the sealed liquefaction conditions than the atmospheric condition.

The spectra of the liquefied wood residue from different $\mathrm{P} / \mathrm{W}$ ratios are shown in Figure 3 . It can be seen that the spectra were very similar except that the intensities at peak $1203 \mathrm{~cm}^{-1}$ increased as the $P / W$ ratio increased. Meanwhile, this peak was absent in the spectra of the original wood and the residue from the atmospheric system (Fig. 2). The absorb- 


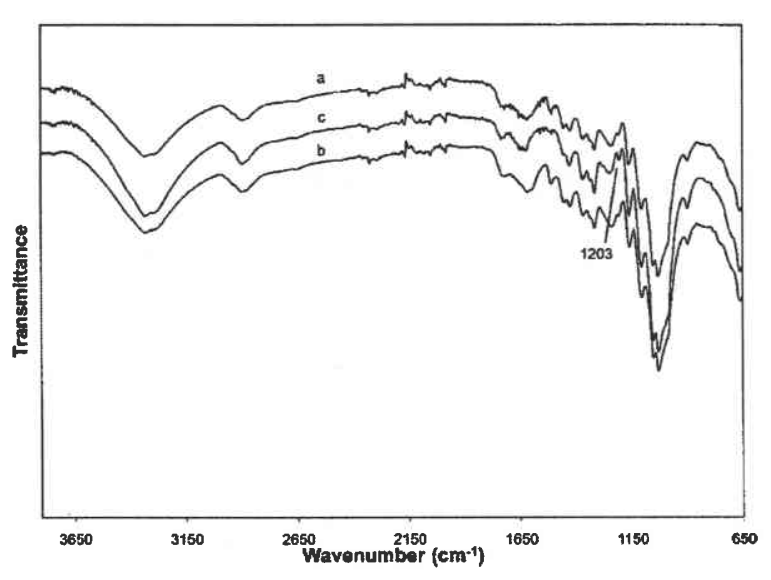

Figure 3 FTIR spectra of residues from $\mathrm{P} / \mathrm{W}$ ratio of $1 / 1$ (Spectrum a), 2/1 (Spectrum b), and $3 / 1$ (Spectrum c) in a sealed liquefaction system at temperature of $150^{\circ} \mathrm{C}$.

ance at $1203 \mathrm{~cm}^{-1}$ is due to the $-\mathrm{OH}$ plane deformation, ${ }^{20}$ indicating that this peak might be related to the phenol-lignin complex retained at the residue.

It is interesting to note that the FTIR analysis of the lignin component of the residue has led to some indications that the spectra changes in the regions 1592,1506 , and $1203 \mathrm{~cm}^{-1}$ were related to the mechanism and characteristic of wood liquefaction. As discussed earlier, however, the determination of lignin content of the liquefied wood residue was related to the amount of the lignin dissolved into the liquefied wood, the extent of the recondensation reaction among the decomposed lignin, and the formation of the insoluble intermediate compounds from the reaction of the phenol and the dissolved lignin. Therefore, the extents of the effects of these reactions on the FTIR spectra are rather complex and difficult to thoroughly understand. To clarify and characterize the possible formation of phenol-lignin compounds and/or recondensation of the decomposed lignin, it is necessary to apply qualitative and quantitative analysis by classical chemical methods together with HPLC and GC-MS. Such experimentation is under consideration.

No significant difference in the spectra of the residues from different temperature was observed (spectra not shown).

\section{$X$-ray diffraction}

The liquefied wood residue displayed a typical $X$ ray diffractogram pattern as that of cellulose I (Fig. 4). In particular, the major diffraction planes of cellulose, namely 101, 101, 002, and 040 are present at diffraction angles $2 \theta$ around $14.9,16.3,22.5$, and $34.6^{\circ}$, respectively. ${ }^{34}$ However, unlike a pure cellulose sample, the peaks of 101 and $10 \overline{1}$ diffraction planes in the X-ray diffractograms of liquefied wood residue overlapped each other and formed one broad peak. This phenomenon was also reported by other researchers ${ }^{35,36}$ and is likely caused by the existence of a small amount of hemicellulose and lignin in the liquefied wood residue.

The X-ray crystallinity index $(\mathrm{CrI})$ of the liquefied wood residues from different liquefaction conditions are listed in Table III. In general, the CrI of the liquefied wood residue is higher than that of the original wood powder and increased as the $P / W$ ratio increased from $1 / 1$ to $3 / 1$ except for the $\mathrm{CrI}$ values of the residue at $\mathrm{P} / \mathrm{W}$ ratio $2 / 1$ and $3 / 1$ were very close in the atmospheric system. This result was expected because of the increasing amount of lignin that was removed from the amorphous region of the liquefied wood residue as the $\mathrm{P} / \mathrm{W}$ ratio increased during the liquefaction process (Table II). It is important to note that the $\mathrm{CrI}$ is used to indicate the relative rather than the absolute amount of the crystalline region in cellulose. ${ }^{35}$ Therefore, when the lignin in the amorphous region decreased, the relative portion of the crystalline region of cellulose increased. A similar result was also found by other researchers. ${ }^{37}$ It is also noted that the residue from the Parr reactor with a $P / W$ ratio of $1 / 1$ had the lowest crystallinity index $(\mathrm{CrI})$ and the highest lignin content. The recondensed lignin should still be a highly branched amorphous polymer. Therefore, the low CrI of the residues from the Parr reactor at $\mathrm{P} / \mathrm{W}$ ratio $1 / 1$ might be due to the high amount of recondensed lignin left in the residue, indicating more severe lignin recondensation reaction in the Parr reactor than the three neck flask. Apparently, the CrI result of the liquefied wood residue is very consistent with the $\alpha$-cellulose content of the liquefied wood residue (Table II). The higher the $\alpha$-cellulose content in the liquefied wood residue, the higher the $\mathrm{CrI}$ value of the liquefied wood residue. In addition,

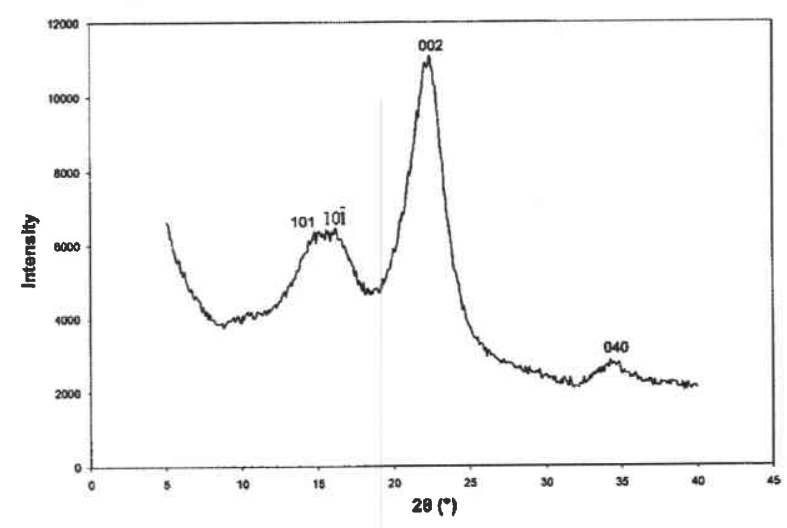

Figure 4 Typical XRD diffractogram of the liquefied wood residue.

Journal of Applied Polymer Science DOI 10.1002/app 
TABLE III

The X-Ray Crystallinity Index (CrI, \%) of the LWR from Different Liquefaction Conditions

\begin{tabular}{|c|c|c|c|c|c|c|c|}
\hline & \multicolumn{3}{|c|}{ At $150^{\circ} \mathrm{C}$} & \multicolumn{3}{|c|}{ At $180^{\circ} \mathrm{C}$} & \multirow{2}{*}{$\begin{array}{c}\text { Original wood } \\
\text { particle }\end{array}$} \\
\hline & $1 / 1$ & $2 / 1$ & $3 / 1$ & $1 / 1$ & $2 / 1$ & $3 / 1$ & \\
\hline $\begin{array}{l}\text { Atmospheric system } \\
\text { Sealed system }\end{array}$ & $\begin{array}{l}55.11(1.37) \\
54.86(0.89)\end{array}$ & $\begin{array}{l}60.18(0.67) \\
62.43(0.71)\end{array}$ & $\begin{array}{l}59.59(1.58) \\
63.72(0.90)\end{array}$ & $\begin{array}{l}58.14(1.77) \\
48.44(1.01)\end{array}$ & $\begin{array}{l}62.60(2.01) \\
60.98(1.24)\end{array}$ & $\begin{array}{l}61.09(0.21) \\
65.87(1.04)\end{array}$ & $45.85(1.73)$ \\
\hline
\end{tabular}

The values within parentheses are the standard deviations of the $\mathrm{CrI}$ values.

150 and $180^{\circ} \mathrm{C}$ are the Liquefaction temperatures.

$1 / 1,2 / 1$, and $3 / 1$ are the Phenol/wood ratios $(w / w)$.

the XRD result of the liquefied wood residue also gives a piece of supporting evidence for an explanation to the result in our previous study. ${ }^{38}$ Namely, the liquefaction rate of the three wood components is in a decreasing order of hemicellulose, lignin, amorphous cellulose, and crystalline cellulose. There is no obvious evidence in this experiment of the liquefaction rate of hemicellulose. However, the lignin did undergo a faster liquefaction rate than the cellulose, thus leaving the crystalline cellulose almost intact in the liquefied wood residue since the crystal structure in cellulose greatly limits the access to $\beta$ 1,4 -glycosidic bonds by reactants and catalysts. ${ }^{39}$ In fact, water is almost completely excluded from the
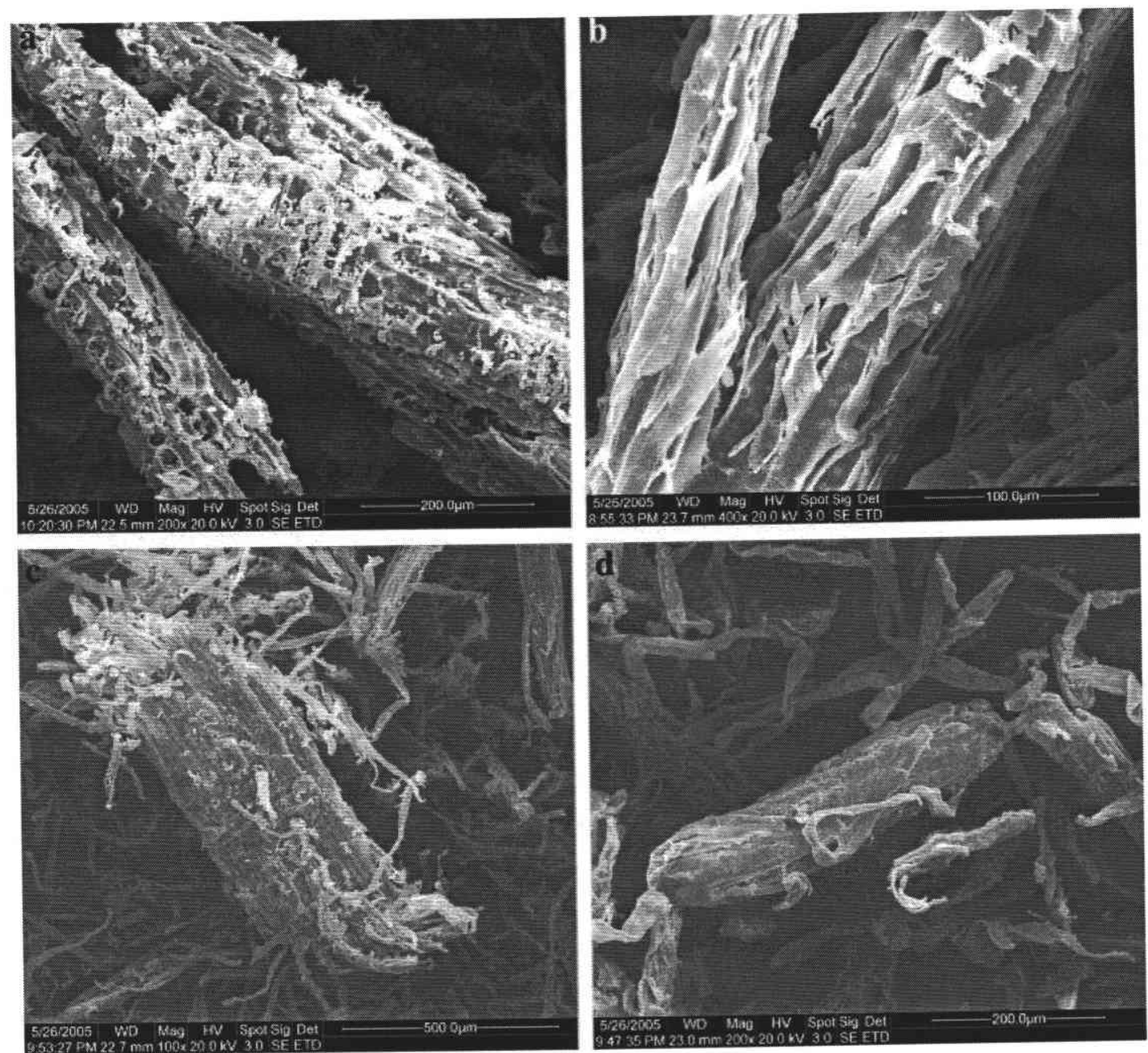

Figure 5 SEM micrographs of the original Chinese tallow tree wood (a), the liquefied wood residue at $\mathrm{P} / \mathrm{W}$ ratio $1 / 1$ (b), $2 / 1(c)$, and $3 / 1(d)$. 
crystalline region in cellulose. ${ }^{39}$ Conversely, the amorphous part of cellulose is more readily accessible by water and other reactants. ${ }^{40}$

\section{Scanning electron microscopy}

The SEM images of original wood powder and the liquefied wood residues from $\mathrm{P} / \mathrm{W}$ ratio $1 / 1$ to $3 / 1$ are shown in Figure $5(a-d)$. The surface of the original wood powder is rough and many small fragments of cell wall components are present due to the mechanical processing procedures [Fig. 5(a)]. As seen from Figure 5(b), most small fragments attached on the surface of the wood powder have been removed at the $P / W$ ratio $1 / 1$, but the liquefied wood residue mostly remained in its original fiber bundles. As the $\mathrm{P} / \mathrm{W}$ ratio increased to $2 / 1$ and $3 / 1$, the fiber bundles started to break down from the two ends to reduce the size of the fiber bundles mainly because the chemical penetration in the longitudinal direction is known to be several times greater than that across the grain of the fiber bundles. As the $\mathrm{P} / \mathrm{W}$ ratio increased, eventually, the bundles were broken down to individual fibers because the lignin, which works as the binding and supporting materials in the middle lamella in wood tissue, had been gradually removed by a peeling effect starting from the outer layer and progressing to inside of the fiber bundles [Fig. 5(c,d)]. These results also correspond well with that of the chemical analyses and XRD.

\section{CONCLUSIONS}

All three experimental variables (e.g., $\mathrm{P} / \mathrm{W}$ ratio, liquefaction temperature, and cooking method) had significant effects on the characteristics of the liquefied wood residues. Higher $\mathrm{P} / \mathrm{W}$ ratio and temperature resulted in lower residue content in the sealed liquefaction system. Lignin is the most susceptible wood component to the liquefaction reaction among the three main wood components and can be mostly removed from wood at a $P / W$ ratio of $3 / 1$ in a sealed reaction system. However, lignin also undergoes a recondensation reaction when there is insufficient reagent solvent (i.e., phenol) in the sealed reaction system. The holocellulose and $\alpha$-cellulose contents of the residues increased with the increase of $\mathrm{P} / \mathrm{W}$ ratio, which is consistent with the decrease of Klason lignin content. The difference in the FTIR spectra of the residues from atmospheric and sealed cooking also confirms the significant effects of these two cooking methods on wood liquefaction and the characteristics of the residues. The CrI of liquefied wood residue is higher than original wood powder and slightly increased as the $\mathrm{P} / \mathrm{W}$ ratio increased, indicating that lignin undergoes a faster liquefaction rate than crystalline cellulose.

The authors gratefully acknowledge the International Bamboo and Rattan Center in Beijing, China for kindly providing the XRD and SEM equipments in this study.

\section{References}

1. Lee, S. H.; Teramoto, Y.; Shiraishi, N. J Appl Polym Sci 2002, $84,468$.

2. Lee, S. H.; Teramoto, Y.; Shiraishi, N. J Appl Polym Sci 2002, $83,1473$.

3. Lin, L.; Hse, C. Y. Holzforschung 2005, 59, 285.

4. Zhang, Y.; lkeda, A.; Hori, N.; Takemura, A.; Ono, H.; Yamada, T. Bioresour Technol 2006, 97, 313.

5. Lin, L.; Yao, Y.; Yoshioka, M.; Shiraishi, N. Holzforschung $2001,55,617$.

6. Lin, L.; Yao, Y.; Yoshioka, M.; Shiraishi, N. Holzforschung $2001,55,625$.

7. American Society for Testing and Materials (ASTM). Standard Test Method for Preparation of Extractive-Free Wood, ASTM, West Conshohocken, 1996. ASTM D 1105-96.

8. American Society for Testing and Materials (ASTM). Standard Test Method for Acid-Insoluble Lignin in Wood, ASTM, West Conshohocken, 1996. ASTM D 1106-96.

9. American Society for Testing and Materials (ASTM). Standard Method of Test for Holocellulose in Wood, ASTM, West Conshohocken, 1971. ASTM D 1104-56.

10. American Society for Testing and Materials (ASTM). Standard Method of Test for $\alpha$-Cellulose in Wood, ASTM, West Conshohocken, 1971. ASTM D 1103-60.

11. Segal, L.; Creely, J. J.; Martin, A. E.; Conrad, C. M. Text Res J $1959,29,786$.

12. Eberhardt, T. L.; Li, X.; Shupe, T. F.; Hse, C. Y. Wood Fiber Sci, to appear.

13. Lin, L. Z. Ph.D. Dissertation, Kyoto University, Kyoto, Japan, 1996.

14. Pur S.; Shiraishi, N. Mokuzai Gakkaishi 1993, 39, 446.

15. Sarkanen, K. V.; In Wood Chemistry; Browning, B.L., Ed.; Interscience: New York, 1963; Chapter 5.

16. Kobayashi, M.; Asano, T.; Kajiyama, M.; Tomita, B. J Wood Sci 2004, $50,407$.

17. Elder, T. In Wood and Cellulosic Chemistry; Hon, D., Shiraishi, N., Eds.; Marcel Dekker: New York, 1990; pp 665-699.

18. Fengel, D.; Wegener, G.; Wood Chemistry, Ultrastructure, Reactions; Walter de Gruyter: Berlin, 1984.

19. Stamm, A. J. Wood and Cellulose Science; The Ronald press company: New York, 1964.

20. Schwanninger, M.; Rodrigues, J. C.; Pereira, H.; Hinterstoisser, B. Vib Spectrosc 2004, 36, 23.

21. Faix, O.; Holzforschung 1991, 45(Suppl.), 21.

22. Vázquez, G.; Antorrena, G.; Freire, S. Holzforschung 1997, 51, 158.

23. Hoareau, W.; Trindade, W. G.; Siegmund, B.; Castellan, A.; Frolini, E. Polym Degrad Stab 2004, 86, 567.

24. Sun, R. C.; Fang, J. M.; Goodwin, A; Lawther, J. M.; Bolton, A. J. Carbohydr Polym 1998, 37, 351.

25. Bjarnestad, S.; Dahlman, O. Anal Chem 2002, 74, 5851.

26. Lojewska, J; Miskowiec, P.; Lojewski, P.; Proniewicz, L. M. Polym Degrad Stab 2005, 88, 512.

27. Sun, J. X.; Mao, F. C.; Sun, X. F.; Sun, R. C. J Wood Chem Technol 2004, 24, 239.

28. Mwaikambo, L. Y.; Ansell, M. P. J Appl Polym Sci 2002, 84, 2222.

29. Cyran, M.; Courtin, C. M.; Delcour, J. A. J Agric Food Chem 2004, 52, 2671.

Journal of Applied Polymer Science DOI 10.1002/app 
30. Kacurakova, M.; Wellner, N.; Ebringerova, A.; Hromadkova, Z.; Wilson, R. H.; Belton, P. S. Food Hydrocolloids 1999, 13, 35.

31. Sun, R. C.; Fang, J. M.; Rowlands, P.; Bolton, J. J Agric Food Chem 1998, 46, 2804.

32. Sun, R. C.; Hughes, S. Carbohydr Polym 1999, 38, 273.

33. Xu, F.; Sun, J. X.; Liu, C. F.; Sun, R. C. Carbohydr Res 2006, 341, 253.

34. Freire, C. S. R.; Silvestre, A. J. D.; Neto, C. P.; Belgacem, M. N.; Gandini, A. J Appl Polym Sci 2006, 100, 1093.

35. Ouajai, S.; Shanks, R. A. Polym Degrad Stab 2005, 89, 327.
36. Garvey, C. J; Parker, I. H.; Simon, G. P. Macromol Chem Phys 2005, 206, 1568.

37. Trindade, W. G.; Hoareau, W.; Megiatto, J. D.; Razera, A. T. Castellan, A.; Frollini, E. Biomacromolecules 2005, 6, 2485.

38. Pan, H.; Shupe, F. T.; Hse, C. Y. In Wood Adhesive 2005; Frihard, C. R., Ed.; Forest Products Society: Madison, WI, 2005; pp 257-262.

39. Zhao, H.; Kwak, J. H.; Wang, Y.; Franz, J. A.; White, J. M.; Holladay, J. E. Energy Fuels 2006, 20, 807.

40. Vittadini, E.; Dickinson, L. C.; Chinachoti, P. C. Carbohydr Polym 2001, 46, 49. 